\title{
Exploring mobile learning development lifecycle with cultural context
}

\author{
Wan Abdul Rahim Wan Mohd Isa, Ahmad Iqbal Hakim Suhaimi, Nurulhuda Noordin, \\ Rabiatul Adawiyah Hashim \\ Faculty of Computer and Mathematical Sciences, Universiti Teknologi MARA, Malaysia
}

\begin{abstract}
Article Info
Article history:

Received Feb 16, 2020

Revised Apr 14, 2020

Accepted Apr 20, 2020

Keywords:

Culture

Mobile development lifecyle

Mobile learning development

Thematic analysis

ABSTRACT

Based on the preliminary study, there are two problems that the development team faces; lack of development model or guideline with culture context for mobile learning developments and lack of cultural context in user interface and user experience of mobile learning development and practices. The main objectives are; (i) to propose Mobile Learning Development Lifecycle Cultural Model and to (ii) assess the proposed Mobile Learning Development Lifecycle Cultural Model. An IT scholar and five IT staff involved in mobile learning development based on the public and private sector at Klang Valley, Malaysia had been chosen for the interview session. The collected data has been analyzed by applying the thematic analysis approach. The first objective was achieved based on IT scholar reviewed on the model proposed. The IT scholar reviewed, (i) challenges on mobile learning development, (ii) theory of Hofstede on the design phase, (iii) user persona on the requirements phase, (iv) advantages of using the proposed model and (v) challenges on Mobile Learning Development Lifecycle Cultural Model. Then, the second objective was achieved by analyzing the qualitative information from the IT staff on the model proposed. The assessment was done by the IT staff for the Mobile Learning Development Lifecycle Cultural Model. There were four primary categories highlighted by the IT staffs which were (i) challenges on mobile learning development, (ii) overcome the challenges, (iii) important elements in mobile learning development and (iv) advantages of Mobile Learning Development Lifecycle Cultural Model. For future work, this study can include more IT scholar and IT staff from diverse positions from multiple organizations.
\end{abstract}

Copyright $(2020$ Institute of Advanced Engineering and Science. All rights reserved.

\section{Corresponding Author:}

Wan Abdul Rahim Wan Mohd Isa,

Faculty of Computer and Mathematical Sciences,

Universiti Teknologi MARA,

40450 Shah Alam, Selangor, Malaysia.

Email: wrahim2@uitm.edu.my

\section{INTRODUCTION}

In general, mobile learning carried out by using portable, hand-held devices and mobile devices [1]. It can be PDA, smartphone or mobile phone. Mobile learning not merely a type of e-learning by handheld devices or an application of classroom education with less formal settings. Mobile learning known as mLearning or m-Learning, encourages learning from anywhere facilitated by a variety of technologies and is not limited to mobile devices.

However, the existing adoption models for mobile learning development lifecycle are the Agile and Mobile Application Development Lifecycle (MADLC). The two models are considered as an alternative for mobile learning development. The Agile models aim to reduce the risk of projects by splitting the project into separate phases, usually the tasks or activities from one week to one month. Every stage is a small project 
including planning, designed, coded, test and documented. The Agile models aim to satisfy users with quick, consistent delivery of meaningful implementation delivered in weeks rather than months [2]. In other words, the Agile model is a productive and responsive attempt to solve user requirements that focus on providing faster and cheaper suitable applications. There are few studies on cloud computing [3-5] that may be relevant to mobile learning development, however, they lack systematic conceptual modeling integration.

The usage of agile principles had been suggested [6]. Figure 1 shows a summary of the literature review to support the conceptual understanding of (i) mobile computing, (ii) mobile learning and (iii) model adoption of the mobile learning development lifecycle. In addition, the cultural context by Hofstede Theory was discussed and addressed. In general, the paper presents results for the qualitative work on the proposed mobile learning development lifecycle cultural model. The main objectives are; (i) to propose Mobile Learning Development Lifecycle Cultural Model and to (ii) assess the proposed Mobile Learning Development Lifecycle Cultural Model.

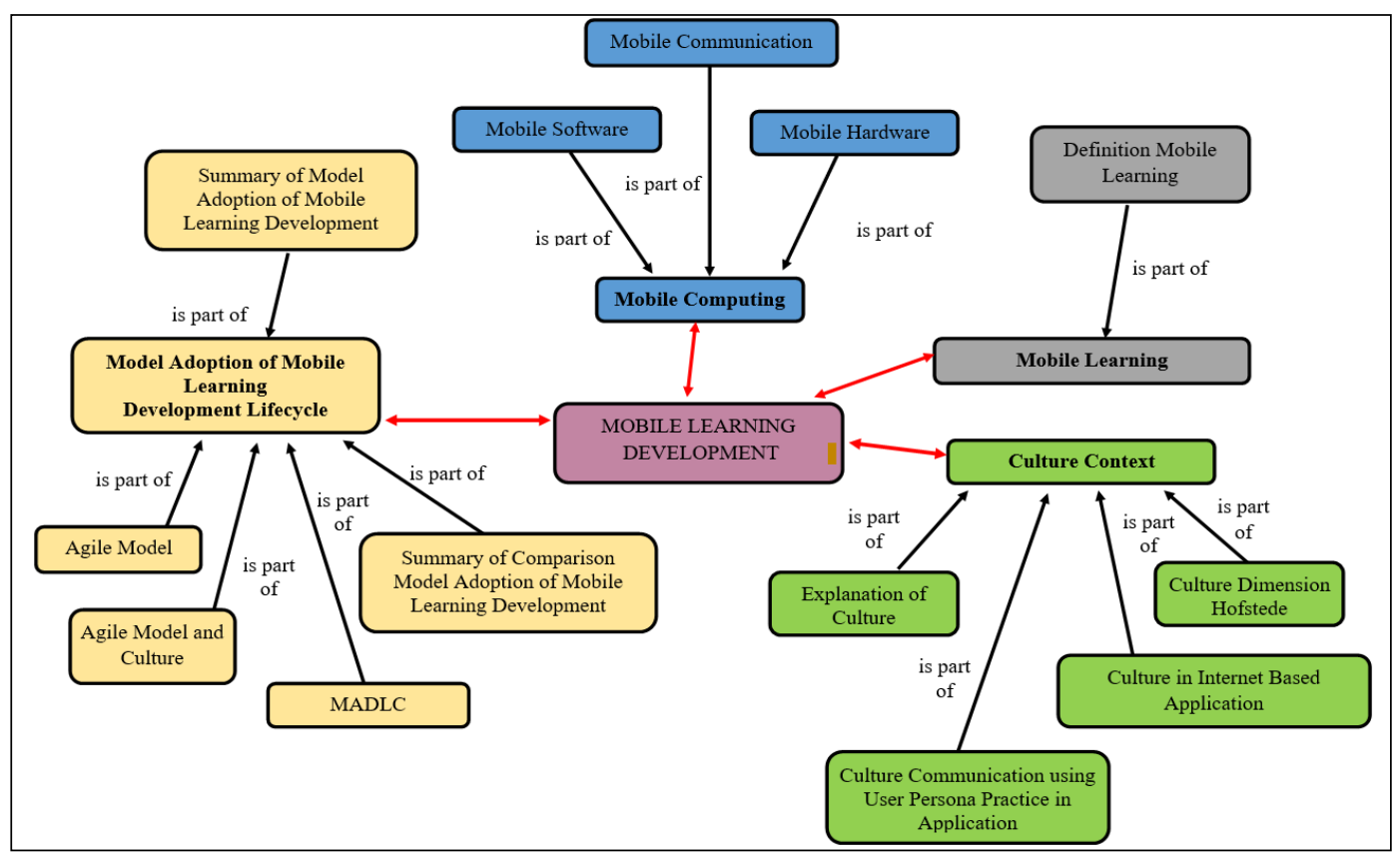

Figure 1. Conceptual mapping of mobile learning development based on literature review

\section{RESEARCH METHOD}

An IT scholar and five IT staff involved in mobile learning development based on the public and private sector at Klang Valley had been chosen for the interview sessions. The collected data had been analyzed by applying the thematic analysis approach. The first objective was achieved based on the IT scholar reviewed on the model proposed. The IT scholar reviewed (i) the challenges in the mobile learning development, (ii) Hofstede theory on the design phase, (iii) User Persona on the requirements phase and the (iv) advantages of Mobile Learning Development Lifecycle Cultural Model. Then, the second objective was achieved by analyzing the information from IT staffs on the model proposed. The IT staff assessed the proposed Mobile Learning Development Lifecycle Cultural Model. There were four primary categories were highlighted by the IT staffs; which were (i) challenges on mobile learning development, (ii) overcome the challenges, (iii) important elements and (iv) advantages of Mobile Learning Development Lifecycle Cultural Model.

\section{ANALYSIS AND FINDINGS}

The analysis and findings from data had been gathered from an IT Scholar and five IT staff from the development team based on the public and private sector at Klang Valley, Malaysia. The crucial part of the research study is the analysis of the data. It can be made from the raw data and context of the research problem. The findings of the interviews are analyzed to fulfill the objectives of the research. Lastly, the final findings and conclusions of the research study are discussed. The Mobile Learning Development Lifecycle Cultural Model and sets of data analysis using qualitative content analysis by applying thematic analysis were discussed. 


\subsection{Mobile learning development lifecycle cultural model}

The first objective is to propose a Mobile Learning Development Lifecycle Cultural Model as shown in Figure 2. It illustrates the information about the phases of mobile learning development with cultural dimensions. The current development demands for mobile learning applications were being incorporated into the development of the model. It comprises of the requirement, design, develop, test, deploy \& release and monitor \& update phases. The Mobile Learning Development Lifecycle Cultural Model also includes Hofstede's cultural dimensions and user persona in the requirement and design phases. Besides that, the proposed model used Hofstede's cultural dimensions to understand the cultural differences and determine how business is carried out across different cultures in mobile learning development particularly in the design phase. Therefore, in the design phase researcher identifying the Hofstede cultural background as a guide [7]. They are the cultural indication on 'Navigation', 'Content' and 'Context' Dimension and also impact of culture on Navigation, Content and Context Dimension of Mobile Learning as shown in Table 1, Table 2 and Table 3. The process model proposed starts from phase 1 until phase 6 including the process of requirement, design, development, test, deploy and release and monitor and update as illustrated in Table 4.

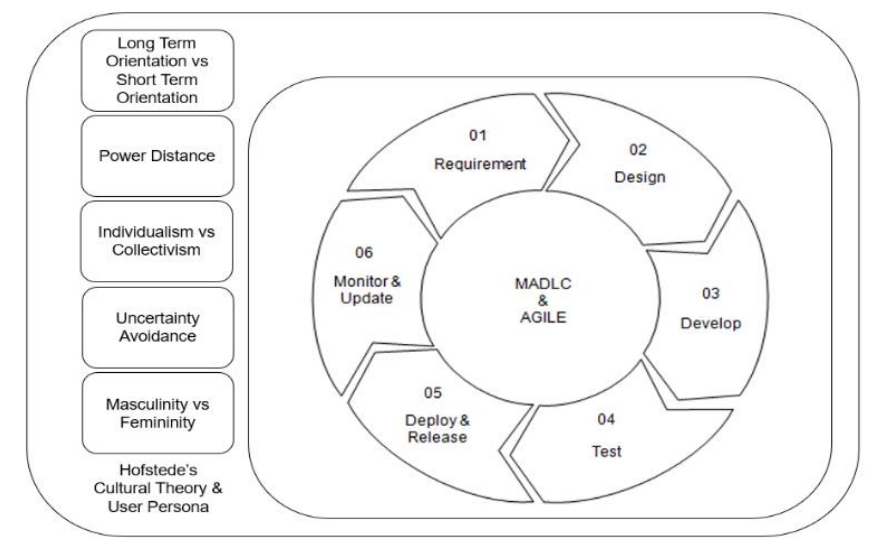

Figure 2. Mobile learning development lifecycle cultural model

Table 1. Adopted general cultural indication to the navigation dimension [7] for mobile learning

\begin{tabular}{cl}
\hline Cultural Dimensions & Navigation Dimension of Mobile Learning (Example) \\
\hline Individualism (IND) & - system for navigation (custom \& global) \\
Collectivism (COL) & - system for navigation to include context \\
High Uncertainty & - Avoid disorientation \\
Avoidance (HUA) & \\
Low Uncertainty & - Navigation (control less) \\
Avoidance (LUA) & \\
Masculinity (MAS) & - More on exploration \\
\hline
\end{tabular}

Table 2. Adopted general cultural indication to the content dimension [7] for mobile learning

\begin{tabular}{ll}
\hline \multicolumn{1}{c}{ Cultural Dimensions } & Content Dimension of Mobile Learning (Example) \\
\hline Individualism (IND) & - Task orientation \\
Collectivism (COL) & - Modular orientation \\
High Power Distance (HPD) & Hierarchy based \\
Low Power Distance (LPD) & Minimal hierarchy included \\
High Uncertainty Avoidance (HUA) & Support mental model \\
Low Uncertainty Avoidance (LUA) & Information organized by task \\
Masculinity (MAS) & Clear role \\
Long Term Orientation (LTO) & Practicality \\
Short TermOrientation (STO) & Incorporate rules and regulation \\
\hline
\end{tabular}

Table 3. Adopted general cultural indication to the context dimension [7] for mobile learning

\begin{tabular}{cl}
\hline Cultural Dimensions & Context Dimension of Mobile Learning (Example) \\
\hline High Power Distance (HPD) & - Portrayal of symbols of identity \\
Low Power Distance (LPD) & - Less portrayal symbols of identity \\
\hline
\end{tabular}


Table 4. Explanation of mobile learning development lifecycle cultural model

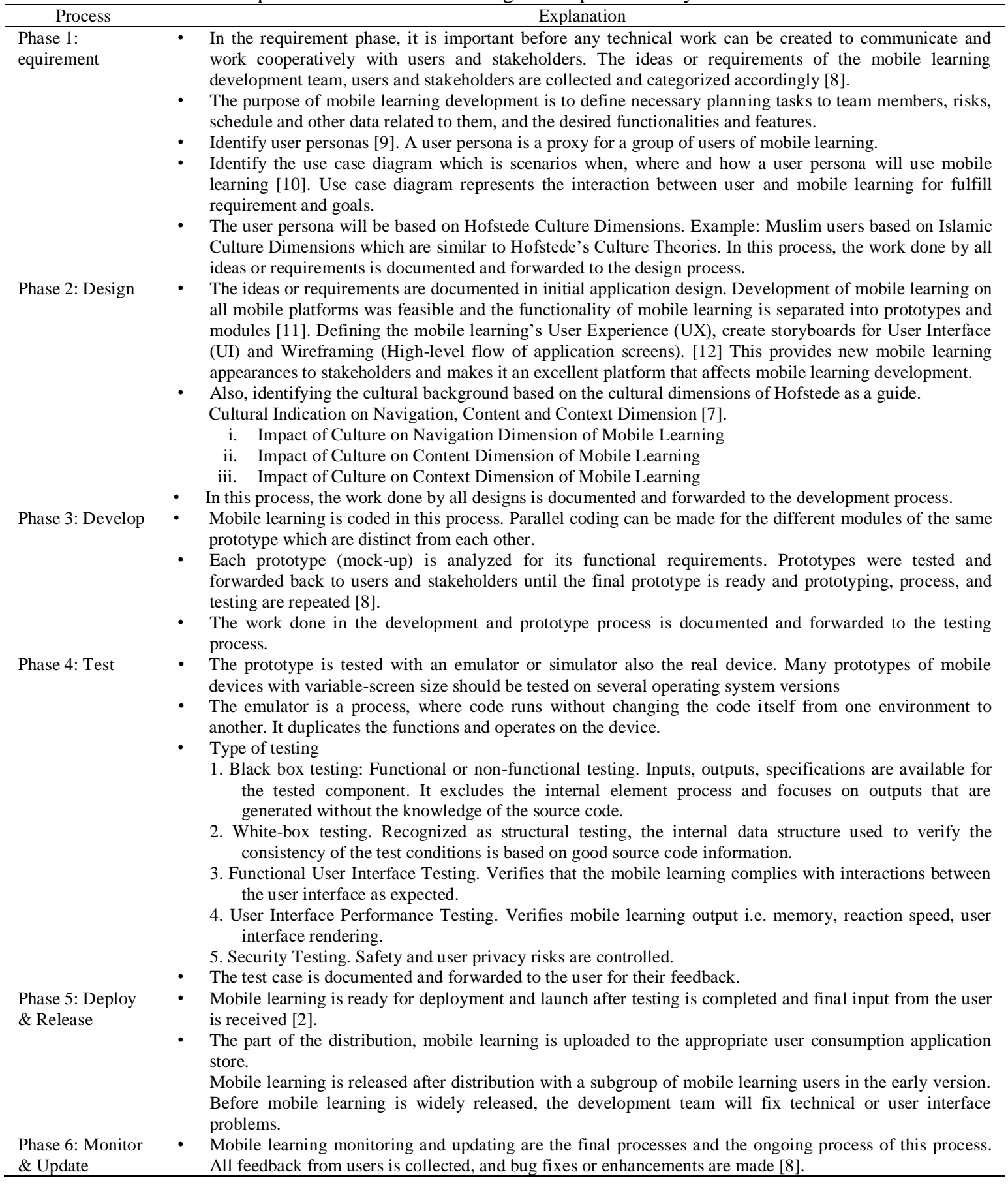

The Mobile Learning Development Lifecycle Cultural Model may also be customized accordingly with integration of relevant results for mobile learning, educational game [13] and mobile applications [14 - 25].

\subsection{Data analysis and interpretation}

Theme 1 is the IT Scholar review on the Mobile Learning Development Lifecycle Cultural Model. Figure 3 illustrates the first theme with the subject IT Scholar review based on Mobile Learning Development Lifecycle Cultural Model. The fifteen reviews had been coded into five main categories which were (i) challenges on mobile learning development, (ii) theory of Hofstede on design phase, (iii) user persona on requirement phase, (iv) advantages of using the model proposed and (v) challenges on Mobile Learning Development Lifecycle Cultural Model. 


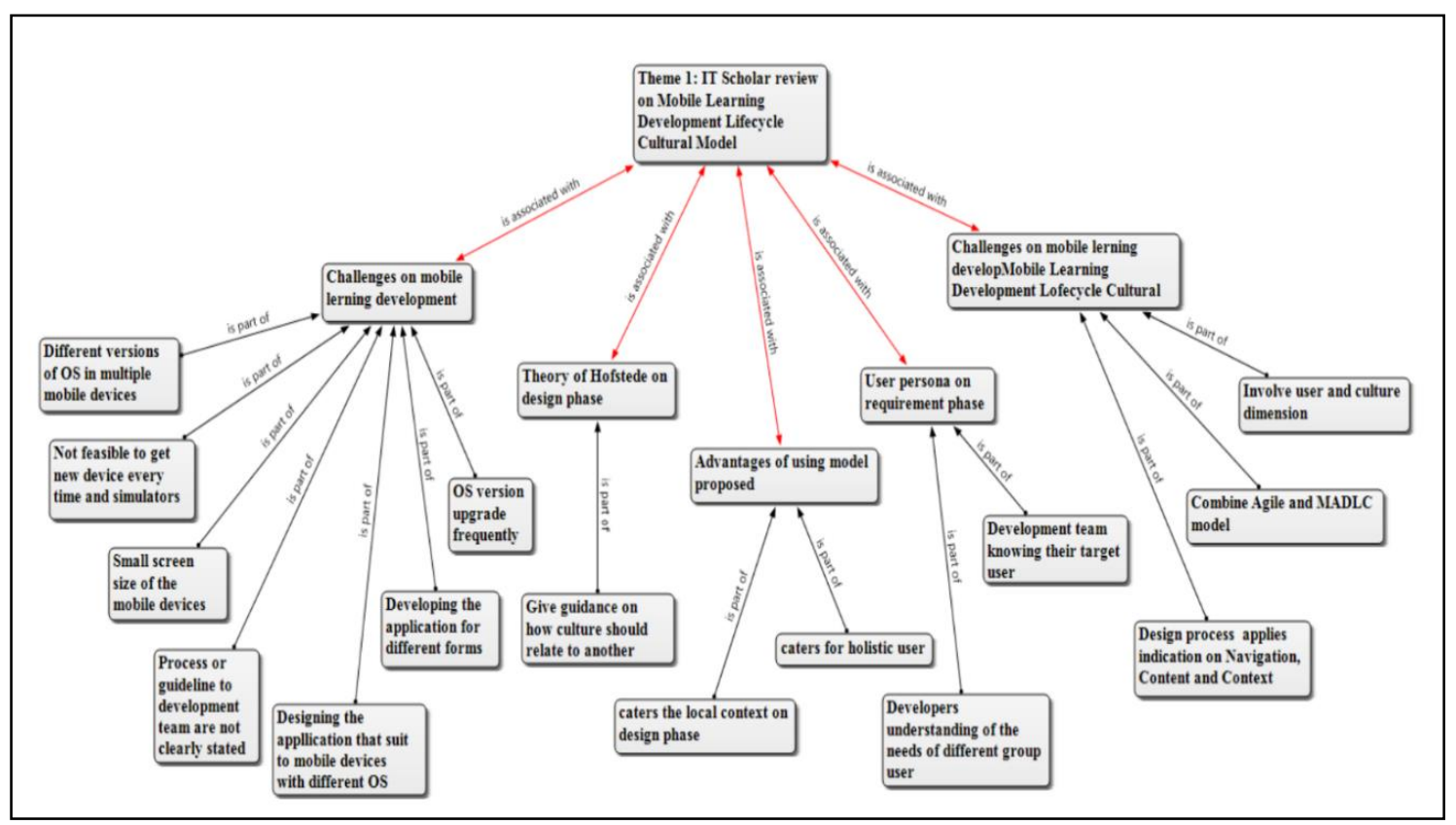

Figure 3. Information technology scholar review on mobile learning development lifecycle cultural model

Theme 2 assessed the proposed Mobile Learning Development Lifecycle Cultural Model. It describes the analysis information from the interview sessions with IT staff such as project manager, system analyst, and the development team review and assessment on the Mobile Learning Development Lifecycle Cultural Model. The qualitative was done to achieve Objective 2, which is to support for Mobile Learning Development Lifecycle Cultural Model as illustrated in Figure 4. The twenty-two review had been coded into four main categories which were (i) challenges on mobile learning development, (ii) overcome the challenges on mobile learning development, (iii) important elements in mobile learning development and (iv) advantages of Mobile Learning Development Lifecycle Cultural Model.

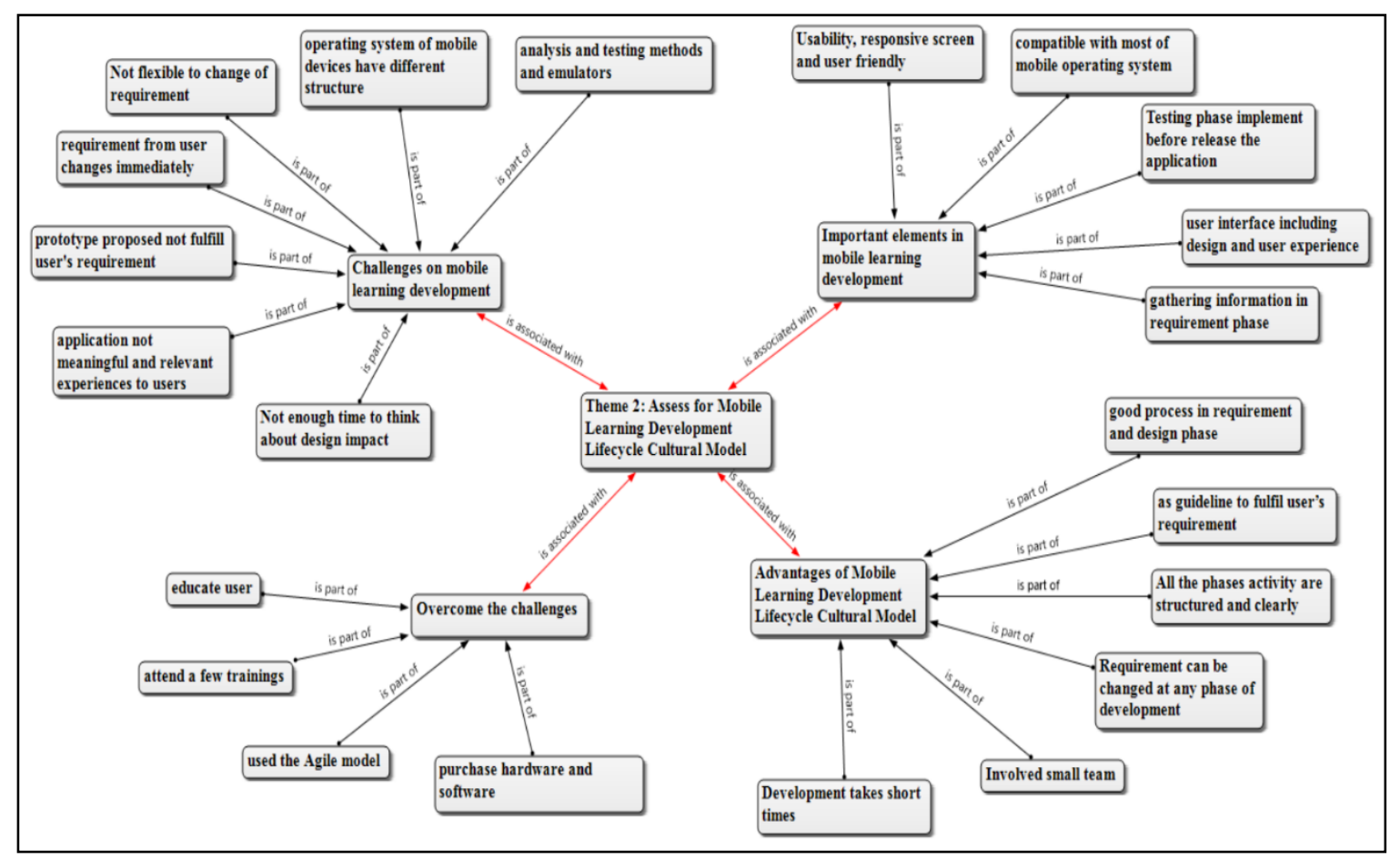

Figure 4. Assessment of the proposed mobile learning development lifecycle cultural model 


\section{CONCLUSION}

Through qualitative review and assessment of the Mobile Learning Development Lifecycle Cultural Model from the IT Scholar and IT Staffs, the research study has achieved its objective and aim to focus on proposing a suitable method in the mobile learning development as future references to the development team of mobile learning with cultural context. Based on the review and assessment done on the proposed model, it is supported that the Mobile Learning Development Lifecycle Cultural Model inclinations towards 'Navigation', 'Content', and 'Context' of the mobile learning are influenced by the culture. The findings and results from the review and assessment of the proposed model are provided important support to the Mobile Learning Development Lifecycle Cultural Model. In conclusion, the research study through the literature review, review and assess the proposed model by IT Scholar and IT staff provide a good understanding of the cultural incorporation of mobile learning development.

\section{ACKNOWLEDGEMENTS}

This research is funded by the Research Entity Initiative (REI), Universiti Teknologi MARA, Malaysia. (Project Code: 600-IRMI/REI 5/3 (013/2018)).

\section{REFERENCES}

[1] G. Vavoula, N. Pachler and A. Kukulska-Hulme, Researching mobile learning: Frameworks, tools and research designs. Bern: Peter Lang, 2009.

[2] A. Majumdar, G. Masiwal and P. M. Chawan, "Analysis of various software process models" International Journal of Engineering Research and Applications, vol. 2, no. 3, pp. 2015-2021, 2012.

[3] R. F. Olanrewaju, T. Islam, O. O. Khalifa, F. E. Fajingbesi, "Data in transit validation for cloud computing using cloud-based algorithm detection of injected objects," Indonesian Journal of Electrical Engineering and Computer Science (IJEECS), vol. 10, no. 1, pp. 348-353, 2018.

[4] W. A. R. Wan Mohd Isa, A. I. H. Suhaimi, N. Noordin, A. F. Harun, J. Ismail and R. Awang Teh, "Factors influencing cloud computing adoption in higher education institution," Indonesian Journal of Electrical Engineering and Computer Science (IJEECS), vol. 17, no. 1, pp. 412-419, 2019.

[5] W. A. R. Wan Mohd Isa, A. I. H. Suhaimi, N. Noordin, A. F. Harun, J. Ismail and R. Awang Teh, "Cloud computing adoption reference model," Indonesian Journal of Electrical Engineering and Computer Science (IJEECS), vol. 16, no. 1, pp. 395 - 400, 2019.

[6] J. Palokangas, "Agile Around the World - How Agile Values Are Interpreted in National Cultures?" MSc Thesis University of Tampere, 2013.

[7] W. M. I. Wan Abdul Rahim, M. N. Nor Laila, M. Shafie, "Incorporating the cultural dimensions into the theoretical framework of website information architecture," In N. Aykin (Ed.), Usability and Internationalization, part 1, HCII2007, LNCS 4559, pp. 212-221, Springer, Berlin, Heidelberg, 2007.

[8] T. Vithani and A. Kumar, "Modeling the mobile application development lifecycle," in International MultiConference of Engineers and Computer Scientists 2014. IMECS 2014, vol. 1, pp. 596-600, 2014.

[9] A. Cooper., The inmates are running the asylum: Why high-tech products drive us crazy and how to restore sanity, Indianapolis, IN: SAMS Publishing, 2004.

[10] B. Dhupia, S. Rubab, and N. Litayem, "Extracting use cases from mobile educational applications requirements," International Journal of Engineering Research \& Technology (IJERT), vol. 4, no. 04, pp. 883-887, 2015.

[11] H. Al-Harrasi, Z. Al-Khanjari and M. Sarrab, "Proposing a new design approach for M-learning applications," International Journal of Software Engineering and Its Applications, vol. 9, no. 11, pp. 11-24, 2015.

[12] R. E. Roth, "User interface and user experience (UI/UX) design," The Geographic Information Science \& Technology Body of Knowledge (2nd Quarter 2017 Edition), John P. Wilson (ed.)., 2017.

[13] T. S. Gunawan, B. Bahari and M. Kartiwi, "Development of Educational Game for primary school mathematics using Microsoft Kinect," Indonesian Journal of Electrical Engineering and Computer Science, vol. 6, no. 2, pp. 457 - 463, 2017.

[14] N. A. Shafin, RD R. Saedudin and N. H. Abdullah, "Implementation of persuasive design principles in mobile application development: a qualitative study," Indonesian Journal of Electrical Engineering and Computer Science, vol. 18, no. 3, pp. 1464 - 1473, 2020.

[15] A. Kaur and K. Kaur, "Effort Estimation in Traditional and Agile Mobile Application Development \& Testing," Indonesian Journal of Electrical Engineering and Computer Science, vol. 12, no. 3, pp. 1265- 1272, 2018.

[16] A. H. Ridwan, I. Safrudin, M. A. Ramdhani and D. R. Ramdania, "Heuristic evaluation on mobile halal detection application," Indonesian Journal of Electrical Engineering and Computer Science, vol. 19, no. 2, pp. 957- 963, 2020.

[17] A. Baharum, E. Abdul Rahim, R. Hanapi, N. A. Mat Noor and N. M. Mohd Yusop, "Evaluating gender-based mobile shopping application using eye-tracking technology," Indonesian Journal of Electrical Engineering and Computer Science, vol. 13, no. 3, pp. 1095 - 1101, 2019.

[18] H. A. Alkaaf, A. Ali, S. M. Shamsuddin and S. Hassan, "Exploring permissions in android applications using ensemble-based extra tree feature selection," Indonesian Journal of Electrical Engineering and Computer Science, vol. 19, no. 1, pp. 543 - 552, 2020. 
[19] A. Qusef, A. Ayasreh, A. Shaout and M. Muhanna, "By two: A two-dimensional mobile game model for novice developers," Indonesian Journal of Electrical Engineering and Computer Science, vol. 14, no. 3, pp. 1336 - 1344, 2019.

[20] R. F. Rahmat, S. Purnamawati, H. Saito, M. F. Ichwan and T. M. Lubis, "Android-based automatic detection and measurement system of highway billboard for tax calculation in indonesia," Indonesian Journal of Electrical Engineering and Computer Science, vol. 14, no. 2, pp. 877 - 886, 2019.

[21] T. S. Gunawan, A. Mutholib and M. Kartiwi, "Design of Automatic Number Plate Recognition on Android Smartphone Platform,” Indonesian Journal of Electrical Engineering and Computer Science, vol. 5, no. 1, pp. 99 - 108, 2017.

[22] A. Mohd, R. A. Rashid, A. H. F. Abdul Hamid, M. A. Sarijari, M. R. A. Rahim, H. Sayuti and M. R. Abdul Rashid, "Development of android-based apps for courier service management," Indonesian Journal of Electrical Engineering and Computer Science, vol. 15, no. 2, pp. 1027 - 1036, 2019.

[23] G. Indrawan, I K. Paramarta, Ketut Agustini and Sariyasa Sariyasa, "Latin-to-Balinese Script Transliteration Method on Mobile Application: A Comparison," Indonesian Journal of Electrical Engineering and Computer Science, vol. 10, no. 3, pp. 1331 - 1342, 2018.

[24] A. N. Rosman, N. A. Samsudin, A. Ismail, M. S. Aripin and S. K. Ahmad Khalid, "Augmented reality application for location finder guidance," Indonesian Journal of Electrical Engineering and Computer Science, vol. 13, no. 3, pp. 1237 - 1242, 2019.

[25] S. Nasir, S. Al-Qaraawi and M. S. Croock, "QR based management system for plants shopping center," Indonesian Journal of Electrical Engineering and Computer Science, vol. 19, no. 2, pp. 931 - 939, 2020. 